\title{
Cross-Cultural Validation of the Inventory of School Motivation (ISM) in the Asian Setting: Hong Kong and the Philippines
}

\author{
Ronnel B. King • Fraide A. Ganotice Jr • \\ David A. Watkins
}

Accepted: 30 May 2011/Published online: 10 June 2011

(C) The Author(s) 2011. This article is published with open access at Springerlink.com

\begin{abstract}
Students' achievement goals in school have received increasing research attention because they have been shown to be important in predicting important outcomes. As such, there has been a growing interest in measuring and comparing them across different cultural groups. However, these comparisons cannot be made until validity evidence has been attained to support the use of an instrument in the new cultural setting. In this study, we investigated the cross-cultural applicability of the Inventory of School Motivation (ISM, McInerney et al. American Educational Research Journal 34:207-236, 1997) in the Hong Kong Chinese and Philippine contexts using both within-network and between-network approaches to construct validation. The ISM measures four types of achievement goals: mastery, performance, social, and extrinsic goals. 1,406 high school students from Hong Kong ( $n=$ $697)$ and the Philippines $(n=709)$ participated. Results of the within-network test showed that the ISM had good internal consistency reliability and the confirmatory factor analysis provided support for the hypothesized four-factor model. Multigroup confirmatory factor analyses supported invariance of factor loadings across the two samples. The between-network test also indicated that these achievement goals correlated systematically with different aspects of students' self-concepts. These findings support the applicability of the ISM among Hong Kong Chinese and Filipino students.
\end{abstract}

Keywords Measurement invariance $\cdot$ Achievement goal orientation $\cdot$ Construct validity $\cdot \mathrm{CFA} \cdot$ Ethnic differences

\footnotetext{
R. B. King $(\bowtie) \cdot$ D. A. Watkins

The University of Hong Kong, Faculty of Education, Room 101 Hui Oi Chow Science Building, Pokfulam, Hong Kong

e-mail: ronnel.king@gmail.com

F. A. Ganotice Jr

Palawan State University, Puerto Princesa, Palawan, Philippines
} 


\section{Introduction}

Students attend school driven by different kinds of goals. Some students go to school with the goal of developing their skills and competence, some with the intention of outperforming others and demonstrating their smartness, others with the end of just being with their friends and peers, and still others to get some sort of reward for their effort. Within the confine of the classrooms, the extent of students' academic engagement and well-being is assumed to be heavily influenced by their goals in school (see Maehr and Zusho 2009 for a review). This underscores the central role played by students' achievement goals, which are defined as the reasons for students' engagement and/or non-engagement in academic-related tasks (Pintrich 2000).

Research on achievement goals has proven generative in educational psychology leading to well over 1,000 published studies and dissertations in the past 25 years since its inception (Hulleman et al. 2010). Achievement goals have been shown to predict both achievement-related and well-being outcomes (Dweck and Legett 1988; Elliot et al. 1999; Kaplan and Maehr 1999; Lau et al. 2008; McGregor and Elliot 2002; McInerney 2008; Sideridis 2005). More specifically, achievement goals have been linked to outcomes such as self-esteem (e.g. Robins and Pals 2002), general well-being (e.g. Dykman 1998; Kaplan and Maehr 1999; Sideridis 2005; Tuominen-Soini et al. 2008), socio-emotional functioning (e.g. Roeser et al. 2002) learning strategies (e.g. Wolters 2004), selfregulated learning (e.g. Pintrich 2000), grades (e.g. Elliot and Murayama 2008), emotions in school (e.g. Pekrun et al. 2006, 2009), self-related beliefs (e.g. Pajares et al. 2000) and other valued educational outcomes (see Elliot 2005 for a review). Despite this productivity, a limitation of achievement goal research is that it only focuses on two types of goals: usually mastery and performance goals. Students with mastery goals want to develop their competence and improve their skill, whereas students with performance goals want to demonstrate their competence before other people and focus on outperforming others (Elliot 2005). Although more recent theorizing on achievement goals has bifurcated the masteryperformance dichotomy into their approach-avoidance dimensions, the central focus of this line of inquiry remains to be these two goals. A focus on these two types of goals seems limiting however when investigating the motivation of students from different cultural settings. Mastery and performance goals have a strong individualist flavor as both give priority to the goals of the individual student with little attention paid to more socially oriented types of goals which are more salient for students from collectivist settings (Tao 2003; Tao and Hong 2000; Watkins et al. 2002a, b). Cross-cultural researchers have noted that other types of goals such as extrinsic goals which entails studying in order to get social recognition and to get material rewards from adults and social goals which focus on achieving for the sake of others are also salient in motivating students from various cultural settings (Dowson and McInerney 2001, 2003, 2004; Salili 1994, 1995; Salili et al. 2001). Kumar and Maehr (2007, p.54) asserted that among students from collectivist cultures, "the motivational goals promoting achievement behavior are extrinsic, utilitarian, and social. They are directed toward achieving upward mobility, recognizing parental sacrifices, fulfilling familial 
obligations of achieving success, and making the family proud-particularly in social comparisons with other families. Achievement and the motives to achieve are, therefore, more social and less individual in collectivistic societies that endorse interdependent selves." Therefore, aside from examining mastery and performance goals, it also seems imperative to assess other types of goals such as social goals and extrinsic goals especially for students from collectivist cultures.

Personal investment theory was designed as an extension of achievement goal theory to specifically address the limitations discussed above (see Maehr and McInerney 2004; McInerney and Liem 2009 for reviews). From its inception, personal investment theory was developed to be a cross-culturally relevant model of students' achievement goals. In this model, four types of goals are proposed to be important in understanding student motivation in school: mastery goals, performance goals, social goals, and extrinsic goals. Each of these goals, in turn, is comprised of two facets (See Table 1).

In line with this, the Inventory of School Motivation (ISM) was then developed to assess the constructs salient to this model (McInerney et al. 1997). It is a 43-item instrument that measures four types of achievement goals: mastery (task and effort), performance (competition and social power), social (affiliation and social concern), and extrinsic goals (praise and token) ${ }^{1}$. Although there is a preponderance of achievement goal measures in the literature (e.g. Elliot and Murayama 2008; Midgley et al. 2000), most of these instruments have been created in the Western context. To the best of the authors' knowledge, only the Inventory of School Motivation (ISM) was specifically developed to look at achievement goals in cross-cultural settings. The ISM incorporates scales that are relevant to examining students' motivation in different cultural contexts (McInerney et al. 2005; 2001; 2003). Research using the ISM has also found consistent relationships between these four types of achievement goals and other valued educational outcomes (Watkins, McInerney, and Boholst 2003; Watkins et al. 2002a, b). For example, the mastery goals scale in the ISM are strongly positively correlated with deep and achieving learning strategies, and negatively correlated with surface strategies. Performance goals and social goals were also positively correlated with deep and achieving learning strategies. Extrinsic goals were positively associated with the surface learning strategies (see McInerney and Liem 2009 for a review). McInerney

\footnotetext{
${ }^{1}$ Each of the four achievement goals in the ISM is comprised of two facets: mastery (task and effort), performance (competition and social status), social (affiliation and concern), and extrinsic (token and praise). In this study, we only validated the ISM at the level of these four goals and we did not focus on the facets that comprised each of these goals. This was done for the sake of parsimony and to be in accord with the existing literature in educational psychology which has mostly looked at mastery and performance goals (see Elliot 2005; Maehr and Zusho 2009 for reviews) and to a lesser extent, extrinsic (McInerney and Liem 2009) and social goals (Dowson and McInerney 2001, 2003, 2004; Urdan and Maehr 1995). In addition, previous empirical research has indicated that the correlation between the two different facets of each of the goals examined were very high (e.g. Ganotice 2010; McInerney and Ali 2006), which puts to question the value of looking at these facets separately. More recent research with the ISM has mostly focused on the four-factor structure of achievement goals in the scale (e.g. Ganotice 2010; Ganotice, Bernardo, \& King, 2010). Thus, in this research we aim to examine the four-factor structure of the ISM through the use of CFA.
} 
Table 1 Four types of achievement goals in personal investment theory

\begin{tabular}{|c|c|c|c|}
\hline $\begin{array}{l}\text { Achievement } \\
\text { goal }\end{array}$ & Facet & Definition & Sample items \\
\hline \multirow[t]{2}{*}{ 1. Mastery goals } & Task involvement & interest in the task & $\begin{array}{l}\text { "The more interesting the } \\
\text { schoolwork the harder I try." }\end{array}$ \\
\hline & Effort & $\begin{array}{l}\text { willingness to expend } \\
\text { effort for schoolwork }\end{array}$ & $\begin{array}{l}\text { "I always try hard to understand } \\
\text { something new in my schoolwork." }\end{array}$ \\
\hline \multirow[t]{2}{*}{$\begin{array}{l}\text { 2. Performance } \\
\text { goals }\end{array}$} & Competition & competitiveness in learning & $\begin{array}{l}\text { "I like to compete with others in } \\
\text { school." }\end{array}$ \\
\hline & Social power & $\begin{array}{l}\text { seeking status through } \\
\text { group leadership }\end{array}$ & "I like being in charge of a group." \\
\hline \multirow[t]{2}{*}{ 3. Social goals } & Affiliation & $\begin{array}{l}\text { belonging to a group } \\
\text { when doing schoolwork }\end{array}$ & $\begin{array}{l}\text { "I can do my best work at school } \\
\text { when I work with others." }\end{array}$ \\
\hline & Concern & concern for other students & $\begin{array}{l}\text { "I like helping other students with } \\
\text { their schoolwork." }\end{array}$ \\
\hline \multirow[t]{2}{*}{ 4. Extrinsic goals } & Token & $\begin{array}{l}\text { seeking tangible rewards } \\
\text { for schoolwork }\end{array}$ & $\begin{array}{l}\text { "Getting a reward for my good } \\
\text { schoolwork is important to me." }\end{array}$ \\
\hline & Praise & $\begin{array}{l}\text { seeking social recognition } \\
\text { for schoolwork }\end{array}$ & $\begin{array}{l}\text { "I work best when I am praised } \\
\text { in school." }\end{array}$ \\
\hline
\end{tabular}

(2008) found that mastery goals were positively associated with well-being in school, while performance, social, and extrinsic goals were not significantly associated with well-being. Mastery goals were also the strongest predictors of educational outcomes such as grades, intention for further schooling, and valuing for school, while the other types of goals such as performance, social, and extrinsic goals were weaker predictors of these outcomes. In an earlier study, McInerney and Sinclair (1991) showed that mastery goals were the strongest predictors of intention to complete high school education among Aboriginal, migrant, and Anglo Australians. Although performance, social, and extrinsic goals were also positive predictors, their effects were weaker and less consistent.

The ISM has been used in Australia involving Aboriginal, Anglo, and migrant-background students (McInerney 2008; McInerney and Sinclair 1991); the United States, involving Navajo and Anglo-American students (McInerney et al. 2001); South Africa, involving both Black and White students (Watkins, McInerney, Akande et al. 2003) and also students from other African countries such as Malawi and Zambia (Watkins et al. 2002a). However, there is still a dearth of studies with regard to the psychometric properties of this instrument in the Asian setting (see Watkins, McInerney, and Boholst 2003 for an exception). Maneesriwongul and Dixon (2004, p. 175) noted that, "Research instruments must be reliable and valid in each culture studied." A further danger inherent in using a psychometric approach in cross-cultural settings is that an assumption may be made by researchers that items and constructs developed and standardized on one particular cultural group are broadly universal when in fact there is no attempt made to demonstrate the applicability of the constructs or 
instruments used to new groups (see McInerney et al. 2001). It is becoming increasingly clear that the methodological and conceptual difficulties involved in capturing behaviors, attitudes and values in cross-cultural studies have been discussed in a lot of studies (van de Vijver and Hambleton 1996; van de Vijver and Poortinga 1982). In response to this observation, it is important that the issue of validity is addressed before the results of such psychological tests with different cultures can be interpreted (Hambleton 2001; van de Vijver and Tanzer 2004). The cross-cultural applicability of the ISM still needs further exploration especially when administered to Asian students. Therefore, in this study, we explored the cross-cultural validity of the ISM in the Chinese and Filipino settings.

\subsection{Approaches to Construct Validation}

The present study adopts a construct validation approach (Marsh 1997; Martin 2007) to the empirical assessment of the cross-cultural applicability of the ISM in the Hong Kong Chinese and Filipino settings. Studies that adopt this approach can be classified as within-network or between-network studies. Within-network construct validation, also called internal construct validation refers to the examination of the factor structure and factor correlation matrix. On the other hand, between-network or external construct validation approach entails examining patterns of relationships between the scales and other theoretically related constructs. The present study uses both approaches. First, we conducted a within-network study using confirmatory factor analysis to test the four factor structure of the ISM separately in the two contexts followed by multigroup confirmatory factor analysis to assess the invariance of the instrument across the two cultures. Consistent with the construct validation approach, it is not only important to address validity within an instrument (within-network validity) but it is also imperative to explore the possible differential relationships between the four types of goals and a set of theoretically relevant measures (between-network validity). In our study, we assessed how the factors in the ISM are related to different aspects of a students' self concept. We expect that these four types of achievement goals will be positively correlated with positive self-concept and negatively correlated with negative self-concept. Positive self-concept refers to positive cognitions about one's ability in school, while negative self-concept refers to negative beliefs about one's ability in school (McInerney 2008). Many studies have shown that self-concept is related to the achievement goals that one adopts (Liem et al. 2008; Pajares et al. 2000; Wolters 2004). Although these studies mostly focused on the relationship of self-related constructs to mastery and performance goals, it is reasonable to assume that the four types of achievement goals (mastery, performance, social, and extrinsic) will all be positively related to positive self-concept and negatively related to negative selfconcept given that these four achievement goals have been shown to be adaptive in collectivist societies (e.g. Cheng 2005; Kumar and Maehr 2007; Tao 2003; Tao and Hong 2000) and have been found to be related to other positive outcome measures (McInerney 2008; Watkins, McInerney, and Boholst 2003). 


\subsection{The Current Study}

This paper adopts both within-network and between-network construct validation approaches to assess the applicability of the ISM in the Chinese and Filipino settings. More specifically, this paper aims to investigate (a) the extent to which the four-factor structure of the ISM which has been found in previous research will be replicated in a Chinese and a Filipino sample, (b) how the interpretations of the different factors of the ISM are different and similar across these two samples, and (c) how the four achievement goals are related to the positive and negative aspects of students' self-concepts in both contexts.

\section{Method}

\subsection{Participants}

Convenience sampling method was used in this study. The Hong Kong Chinese sample consisted of 697 high school students $(M$ age $=13.43$ years, $S D=1.37$ years, median $=14$ years). The sample consisted of 356 women $(51.07 \%)$ and 341 men (48.92). Of these 241 were from a high-ability school, 230 from a medium-ability school, and 226 were from a low ability school ${ }^{2}$. The Filipino sample, on the other hand, consisted of 709 high school adolescent students $(M$ age $=14.56$ years, $S D=$ 0.89 years, median age $=14$ years $)$ of which there were 195 males $(27.50 \%)$ and 514 $(72.49 \%)$ females. The Filipino students were approximately equally distributed between those from private schools and public schools ${ }^{3}$. Taken together, there were 1,406 adolescent high school students which comprised the participants of this study.

\subsection{Procedure}

Students were required to complete the inventory as part of the class requirement. They were assured that their responses would remain confidential and would not, in any way, influence their course grade. The measures described below were completed by students from both contexts.

\subsection{Measures}

In this study, we utilized the Chinese version (Watkins et al. 2002a) and Filipino version (Ganotice et al. 2010) of the Inventory of School Motivation for the Hong Kong and Filipino students respectively. It is rated on a 5-point Likert scale with 1 as "strongly disagree" and 5 as "strongly agree." Higher scores would entail a greater endorsement of the relevant construct. Table 2 contains sample Chinese and Filipino items for each of the constructs.

\footnotetext{
${ }^{2}$ The Education Bureau in Hong Kong classifies schools into three types or bands: high ability schools also called Band 1 schools; medium-ability schools also called Band 2 schools, and low-ability schools or Band 3 schools. This classification system is derived based on the internal assessment results.

${ }^{3}$ In the Philippines, the most salient classification involves the distinction between public and private schools (see Chua 2000, 2008).
} 
Table 2 Sample items for the Chinese and Filipino versions of the ISM

\begin{tabular}{|c|c|c|c|}
\hline $\begin{array}{l}\text { Achievement } \\
\text { goals }\end{array}$ & English version & $\begin{array}{l}\text { Sample item } \\
\text { (Chinese) }\end{array}$ & Sample item (Filipino) \\
\hline $\begin{array}{r}\text { Mastery } \\
\text { Goals }\end{array}$ & $\begin{array}{l}\text { I like being given the } \\
\text { chance to do something } \\
\text { again to make it better. }\end{array}$ & $\begin{array}{l}\text { 我希望被给予机会 } \\
\text { 去重做某些事情 } \\
\text { 以将其改善. }\end{array}$ & $\begin{array}{l}\text { Gusto kong mabigyan ng pagkakataon na } \\
\text { gawing muli ang isang bagay nang mas } \\
\text { magaling. }\end{array}$ \\
\hline $\begin{array}{l}\text { Performance } \\
\text { Goals }\end{array}$ & Winning is important to me. & $\begin{array}{c}\text { 获得胜利对我来说 } \\
\text { 是重要的. }\end{array}$ & Ang magtagumpay ay importante sa akin. \\
\hline Social Goals & $\begin{array}{l}\text { It is very important for } \\
\text { students to help each other } \\
\text { at school. }\end{array}$ & $\begin{array}{l}\text { 在学校, 同学们互 } \\
\text { 相帮助是非常重 } \\
\text { 要的. }\end{array}$ & $\begin{array}{l}\text { Napaka-importante para sa mga } \\
\text { estudyante na mag tulungan ang bawat } \\
\text { isa sa paaralan. }\end{array}$ \\
\hline $\begin{array}{l}\text { Extrinsic } \\
\text { Goals }\end{array}$ & $\begin{array}{l}\text { Praise from my teachers for } \\
\text { my good schoolwork is } \\
\text { important to me. }\end{array}$ & $\begin{array}{l}\text { 我重视老师对我良 } \\
\text { 好学业表现的赞 } \\
\text { 赏. }\end{array}$ & $\begin{array}{l}\text { Ang mga papuri mula sa aking mga guro } \\
\text { tungkol sa aking mabuting schoolwork } \\
\text { ay importante sa akin. }\end{array}$ \\
\hline
\end{tabular}

Aside from the ISM, we also administered the positive and negative self-concept subscales of the Sense of Self (SoS) Scale. We administered the Chinese version (Watkins et al. 2002a) to the Hong Kong students and the Filipino version (Ganotice and Bernardo 2010) to the Filipino students. Positive self-concept measures the students' positive cognitions about general academic ability in the school setting (e.g. "I can succeed at whatever I do in school.") while negative self-concept measures negative cognitions about general academic ability at school (e.g. "I often make mistakes at school."). Reliabilities for these scales were generally acceptable. For the HK sample, the Cronbach's alpha for negative self-concept was .58 and .70 for positive self-concept. For the Filipino sample, the alpha for the negative self-concept was .80 and .75 for the positive self-concept.

\section{Results}

\subsection{Preliminary Analysis}

Preliminary analysis was performed to check the properties of data. No outliers were found. Tables 3 and 4 present descriptive statistics and internal consistency coefficients for the different subscales in the ISM in the two cultural contexts. Cronbach's alpha coefficients were calculated for each of the scales for the data on

Table 3 Descriptive statistics and internal consistency coefficients for the Hong Kong sample $(N=697)$

\begin{tabular}{lccc}
\hline & Mean & SD & Cronbach's alpha \\
\hline 1. Mastery goals & 3.72 & .45 & .74 \\
2. Performance goals & 3.01 & .57 & .82 \\
3. Social goals & 3.53 & .48 & .73 \\
4. Extrinsic goals & 3.09 & .57 & .83 \\
\hline
\end{tabular}


Table 4 Descriptive statistics and internal consistency coefficients for the Philippine sample $(N=709)$

\begin{tabular}{lccc}
\hline & Mean & SD & Cronbach's alpha \\
\hline 1. Mastery goals & 3.34 & .39 & .72 \\
2. Performance goals & 3.89 & .30 & .78 \\
3. Social goals & 3.07 & .52 & .73 \\
4. Extrinsic goals & 2.90 & .60 & .84 \\
\hline
\end{tabular}

English and Filipino versions. Reliability estimates were all acceptable and varied from .70 to .83 for the Hong Kong data .72 to .84 for the Philippine data.

\subsection{Confirmatory Factor Analysis (CFA)}

Normality was assessed by examining skewness and kurtosis values for each item. Absolute values of skewness and kurtosis beyond 2 and 7, respectively, may imply a lack of univariate normality (Finney and DiStefano 2006). For the HK data, skewness values ranged from -.64 to .23; while kurtosis values ranged from -.07 to 1.04. For the Philippine sample, skewness ranged from .19 to .98 , while kurtosis ranged from -.56 to 1.31. Skewness and kurtosis values for the two samples did not exceed the recommended values.

We also checked for outliers by looking at the Mahalanobis distance $\left(\mathrm{D}^{2}\right)$. Values that stand distinctively apart from other values can be considered outliers. No such outliers were found for both the Hong Kong and Philippine samples. Given that the data appear normally distributed, maximum likelihood (ML) estimation was employed to estimate model parameters and fit indices.

Two separate CFAs were first conducted, one for the Hong Kong sample and the other for the Filipino sample. All the calculations were done using AMOS 16.0 (Arbuckle 2007) The CFA procedure was used to assess the extent to which the observed data reflected or fit the proposed four-factor model or structure of the 43item ISM. Bagozzi and Heatherton (1994) suggested that it is quite likely that having more than five indicators per factor in a large sample would to lead to an unsatisfactory fit in the measurement model. To address this issue, we aggregated the items to form item "parcels" as indicators in the CFA. A parcel is defined as an aggregate-level indicator comprised of the sum or average of two or more items, responses, or behaviors. To create the parcels, we randomly assigned each item in a factor to one parcel grouping. Random assignment of two to four items to parcels should, on average, lead to parcels that contain roughly equal common factor variance (Little et al. 2002). This method of parceling was recommended by Little et al. (2002) when all items are answered on the same metric and when items can be considered unidimensional (for example, as verified through previous studies involving exploratory factor analysis). Given that all the items in the ISM were answered using a 5-point Likert scale and that previous studies have identified its four-factor structure (e.g. McInerney and Ali 2006), we decided to use random assignment of parcels. Using parcels is believed to increase the reliabilities of the indicator variables, and reduces the likelihood that parameters will be affected by item-specific variance (Lance et al. 1991). Moreover, the distribution of the parcels are more likely to approximate a normal distribution better than the distribution of 
individual items, and the results based on parcels are more likely to be stable (i.e. generalizable) across samples (West et al. 1995). Eleven parcels were created from the 43 items of the Inventory of School Motivation. There were three to four randomly assigned items for each parcel, with the average of the items being used as the parcel score.

Several goodness-of-fit indices were used to determining the model fit, based on the understanding that multiple indices provided a comprehensive evaluation of model fit (Hu and Bentler 1995, 1999). The following fit indices used were: the chisquare $\left(\chi^{2}\right)$, ratio of chi-square values to the degrees of freedom $\left(\chi^{2} / \mathrm{df}\right)$; root mean square error of approximation (RMSEA), goodness of fit index (GFI), comparative fit index (CFI), normed fit index (NFI), incremental fit index (IFI), Tucker-Lewis Index (TLI), and the comparative fit index (CFI). The criterion values were set based on the prescriptions summarized in Schermelleh-Engel et al. (2003; see also Bentler 1990). The chi square statistic should be non-significant. For RMSEA, values less than.08 indicate acceptable fit. GFI, NFI, IFI, TLI, and CFI values higher than .90 shows acceptable fit. The fit indices for the CFAs for the two language version data are shown in Table 5.

Results of the separate confirmatory factor analysis for the Hong Kong and the Philippine samples indicated a good fit. GFI, NFI, IFI, TLI, and CFI were all above .90 , while RMSEA was below $.08^{4}$. Only the chi square statistic was not satisfactory in the CFA (See Table 5). A statistically non-significant chi square value indicates that the model is a reasonably satisfactory representation of the data. However, as noted by Anderson and Gerbing (1988), the value of the chi-square statistic is dependent on sample size. As such, data that involve a large sample size will likely have a chi-square statistic that is significant although there are only minor discrepancies between the model and the data. Because of this, we decided to focus on the other goodness of fit indices which all indicate a good fit. The results showed good fit indices for both the Chinese and Filipino versions. The results of the CFA shows strong support for the four-factor structure of both the Chinese and Filipino versions of ISM (see Figs. 1 and 2).

\subsection{Multigroup Confirmatory Factor Analysis Results}

To test for the invariance of the ISM across the two cultural contexts, we followed a stepwise procedure. For the first model, we tested for configural invariance which indicates whether the number of factors and pattern of indicator-factor loadings is identical. The second model holds the factor loadings invariant, the third model holds both factor loadings and factor variances and covariances invariant. Although the chi-square difference test has traditionally been used in multigroup CFA to test between competing models, Cheung and Rensvold (2002) argued that from an applied perspective this may be overly restrictive. They indicated that a decrease of

\footnotetext{
${ }^{4}$ Alternative methods of random parceling were done, with different items being assigned to different parcel groups. The alternative models fit the data equally well as the CFA presented above. Goodness-offit indices were largely similar to the one presented above and non-significant chi square differences further supported the similarity of the different methods of parceling.
} 
Table 5 Summary of the goodness-of-fit statistics

\begin{tabular}{lllllllllll}
\hline Model & $\chi^{2}$ & $d f$ & $\chi^{2} / d f$ & $p$ & RMSEA & GFI & NFI & IFI & TLI & CFI \\
\hline Hong Kong & 201.333 & 38 & 5.298 & $p<.001$ & .079 & .950 & .936 & .948 & .924 & .947 \\
Philippines & 170.551 & 38 & 4.488 & $p<.001$ & .070 & .953 & .949 & .960 & .942 & .960
\end{tabular}

$\chi^{2}$ chi-square, $d f$ degrees of freedom; $\chi^{2} / d f$ chisquare to degrees of freedom ratio; RMSEA root mean square error of approximation; NFI normed fit index; IFI incremental fix index; TLI Tucker-Lewis index; CFI comparative fit index

0.01 in the CFI is evidence for lack of invariance. Following this suggestion, the results show that there is invariance of factor loadings for the Hong Kong and Filipino samples (See Table 6). However, there was no evidence of structural invariance. It appears that the relationships among the latent factors were not similar in the two cultural settings.

\subsection{Between-Network Construct Validity Results}

To assess between-network validity, we examined the relationship of the ISM scales to positive and negative self-concept. It is assumed that the four types of achievement goals will be positively correlated to students' positive self-concept and negatively correlated with negative self-concept. Results of the bivariate correlations generally supported this assumption.

Results of the between-network construct validation indicate a generally similar pattern of relationships between students' self-concepts and the four types of motivational goals (See Tables 7 and 8). Broadly speaking, the four types of

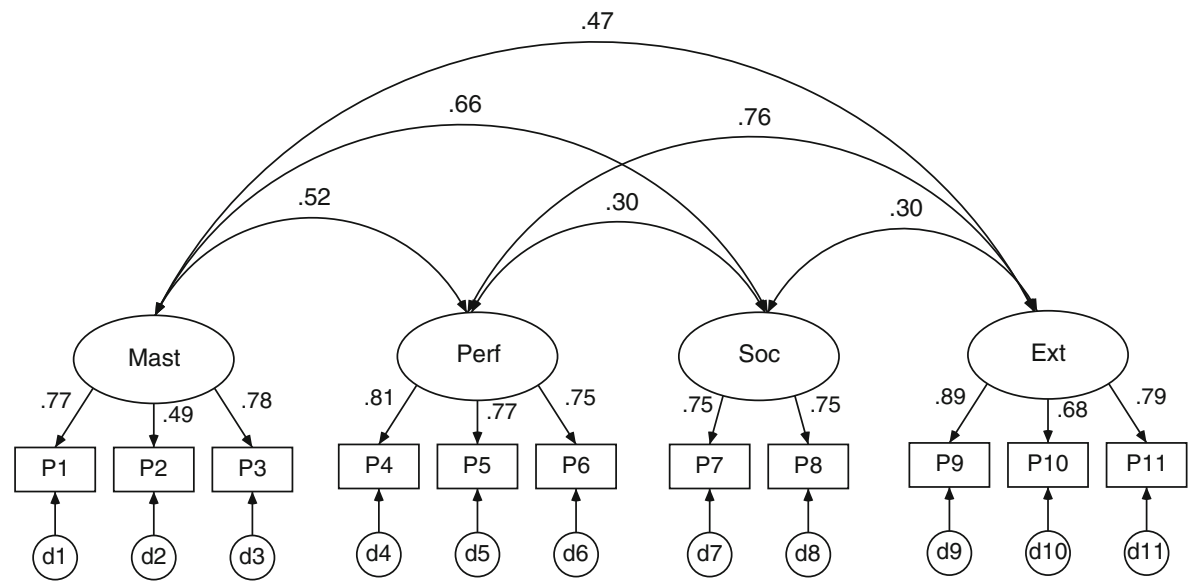

Fig. 1 Confirmatory factor analysis of the 11 parcels of the Chinese version of the Inventory of School Motivation (ISM) with 4 factors. Inter-factorial correlations and factor loadings indicated are all significantly different from zero at $p<.001$ Note: Mast $=$ mastery goals, Perf $=$ performance goals, Soc $=$ social goals, Ext $=$ extrinsic goals, $\mathrm{P}=$ parcel, $\mathrm{d}=$ error or disturbance 


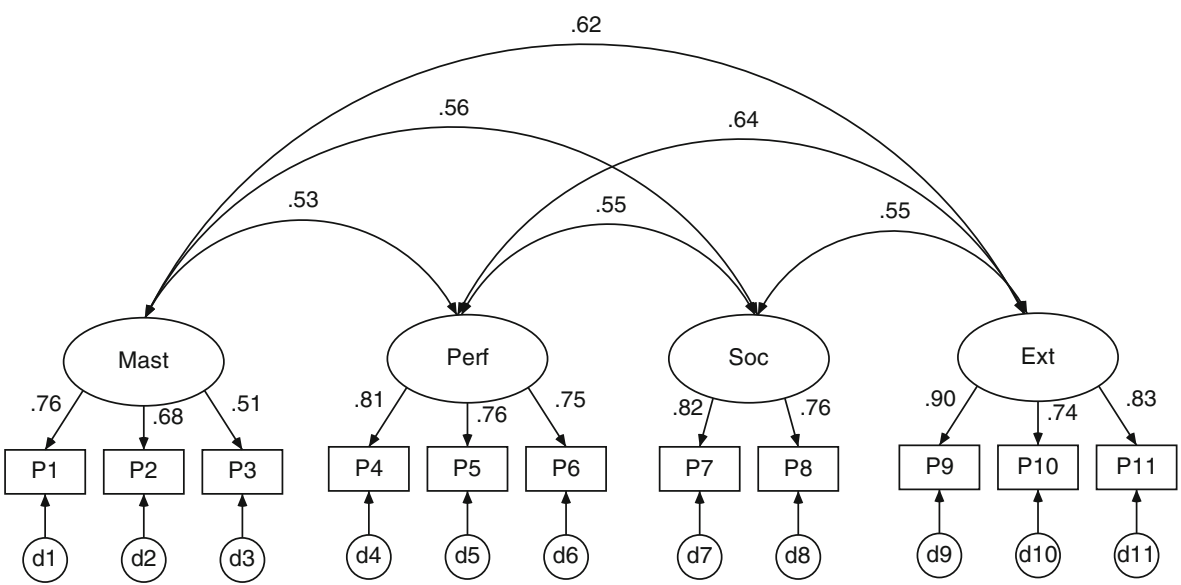

Fig. 2 Confirmatory factor analysis of the 11 parcels of the Filipino version of the Inventory of School Motivation (ISM) with 4 factors. Inter-factorial correlations and factor loadings indicated that they are all significantly different from zero at $p<.001$ Note: Mast $=$ mastery goals, Perf $=$ performance goals, Soc $=$ social goals, Ext $=$ extrinsic, $\mathrm{P}=$ parcel, $\mathrm{d}=$ error or disturbance

achievement goals were positively correlated with positive self-concept and negatively correlated with negative self-concept. However, there was a slight difference with regard to the relationship between performance goals and negative self-concept. The relationship was not significant in the HK sample but significant in the Philippine sample. Extrinsic goals were negatively correlated to negative selfconcept in the Philippine sample but not in the HK sample.

\section{Discussion}

The central objective of this inquiry was to examine the cross-cultural validity of the ISM in the Chinese and Filipino contexts using both within-network and between-

Table 6 Invariance testing across Hong Kong Chinese and Filipino students

\begin{tabular}{lllllllllllll}
\hline Model & $\chi^{2}$ & $d f$ & $\chi^{2} / d f$ & $\mathrm{p}$ & RMSEA & GFI & NFI & IFI & TLI & CFI & $\begin{array}{c}\text { Change } \\
\text { in CFI }\end{array}$ \\
\hline $\begin{array}{l}\text { 1. Configural } \\
\text { invariance }\end{array}$ & 371.885 & 76 & 4.893 & $p<.001$ & .053 & .953 & .943 & .954 & .933 & .954 & \\
$\begin{array}{l}\text { 2. Invariant } \\
\text { factor loadings }\end{array}$ & 407.325 & 83 & 4.908 & $p<.001$ & .053 & .949 & .938 & .950 & .933 & .949 & .005 \\
$\begin{array}{c}\text { 3. Invariant factor } \\
\text { variances and } \\
\text { covariances }\end{array}$ & 506.149 & 93 & 5.442 & $p<.001$ & .056 & .937 & .922 & .936 & .924 & .936 & .013 \\
\hline
\end{tabular}

$\chi^{2}$ chi-square, df degrees of freedom; $\chi^{2} / d f$ chisquare to degrees of freedom ratio; RMSEA root mean square error of approximation; NFI normed fit index; IFI incremental fix index; TLI Tucker-Lewis index; CFI comparative fit index 
Table 7 Zero-order correlations among the ISM goals and students' self-concepts in the Hong Kong sample

$* * * p<.001$

Positive self-concept Negative self-concept

\begin{tabular}{lll}
\hline 1. Mastery goals & $.306^{* * *}$ & $-.162^{* * *}$ \\
2. Performance goals & $.274^{* * *}$ & .067 \\
3. Social goals & $.252^{* * *}$ & $-.195^{* * *}$ \\
4. Extrinsic goals & $.218^{* * *}$ & .090 \\
\hline
\end{tabular}

network construct validation approaches. Overall, results supported the validity of this instrument in the two cultural contexts.

For the within-network test, we focused on the Cronbach's alpha reliabilities and the separate CFA results of the ISM in the two cultural settings. The Cronbach's alpha reliabilities for the ISM subscales in the Hong Kong setting were acceptable ranging from .73 to .83 . For the Philippine sample the reliabilities ranged from .72 to .84 . These values are generally similar to what has been reported previously in the literature when ISM was used with different cultural groups such as Australian, Aboriginal Australian, Anglo-American, and American Indian students (see McInerney and Ali 2006 for a summary). With regard to the separate CFAs, the data confirmed a good fit of the four-factor achievement goal model in both the Hong Kong and Philippine samples. The four-factor structure of achievement goals posited in Maehr and McInerney's (2004) personal investment theory was replicated in these two samples. Mastery goals, performance goals, extrinsic goals, and social goals represent distinct but inter-related constructs. The RMSEAs were lower than the cutoff of .08 for an adequate model (RMSEAs $=.079$ and .070 in Hong Kong and the Philippines respectively). In addition, the GFI, IFI, TLI, and CFI were all above .90 in both samples.

The replication of the four-factor structure of achievement goals in our study is important because most of the achievement goal measures in the literature (e.g. Elliot and Church 1997; Elliot and Murayama 2008; Midgley et al. 2000) only focus on mastery and performance goals although more recent scales have included the approach and avoidance dimensions of these two goals. However, mastery and performance goals even including their approach avoidance dimensions still give too much priority to the goals of the individual. Extrinsic goals such as studying in order to get social recognition and material rewards from adults and social goals which focus on enhancing a sense of membership to the group have been found to be especially salient in collectivist settings (Bernardo 2008; Bernardo et al. 2008; Chang and Wong 2008; Yu and Yang 1994). Therefore, aside from examining mastery and performance goals, it also seems imperative to assess other types of goals such as social goals and extrinsic goals especially for students from collectivist

Table 8 Zero-order correlations among the ISM goals and students' self-concepts in the Philippine sample
$* * * p<.001$

\begin{tabular}{lcc}
\hline & Positive self-concept & Negative self-concept \\
\hline 1. Mastery goals & $.387^{* * *}$ & $-.396^{* * *}$ \\
2. Performance goals & $.430^{* * *}$ & $-.369^{* * *}$ \\
3. Social goals & $.364^{* * *}$ & $-.384^{* * *}$ \\
4. Extrinsic goals & $.394^{* * *}$ & $-.326^{* * *}$
\end{tabular}


cultures. Social goals and extrinsic goals are also important facets of student motivation thus a fuller picture can be captured if the ISM were used because it can measure a wider range of goals compared to that normally investigated within achievement goal theory. An argument that frequently comes up with the use of a more complex perspective like personal investment theory and the use of the lengthier ISM is that it sacrifices parsimony and researchers wonder whether such a sacrifice is justified. McInerney and Liem (2009, p. 230) in their debate with more traditional achievement goal theorists wrote, "Effectively PI theory is far more complex than goal theory, but life and motivated behaviours are complex and should not be reduced to simple dimensions." They argue further that in cross-cultural settings, personal investment theory offers a "potentially, a far richer and more sensitive source of information on the motivational determinants of achievement behaviour. Particularly...in socioculturally diverse settings." It seems that ISM has an advantage over other achievement goal measures in that it can also capture social and extrinsic goals while at the same time taking into account mastery and performance goals which have been the focus of most achievement goal theorists. Such an approach offers a more nuanced perspective on student motivation. Studies using the ISM have supported the benefits of using this instrument. For example, researchers have acknowledged that social goals are also important factors to consider in examining student motivation. However, to date, there is still a dearth of knowledge with regard to how social goals influence important academic outcomes (Urdan and Maehr 1995). Studies using the ISM in diverse cultural settings has shown that social goals are also related to positive learning outcomes such as deep learning strategies (Watkins et al. 2002a, b).

Eccles et al. (1998) claimed that “categorizing children's goals as ego (performance) or task involved (mastery) oversimplifies the complexity of motivation" (p. 1032). In addition, Maehr (1984) argued that although gaining (i.e. mastery goals) and demonstrating academic competence (i.e. performance goals) may be of concern to all individuals some of the time, it is not necessarily the central concern in any given setting or time. He argued that "other goals, other intentions, other attractions, continually intrude" (p. 116). The ISM offers a viable alternative to the other achievement goal measures in the literature that only focus on mastery and performance goals.

Through the multigroup CFA, we found evidence of configural invariance and weak measurement invariance. Configural invariance refers to the invariance of the model configuration, i.e. the pattern of free and fixed model parameters. Weak measurement invariance means that the factor loadings were equivalent in the two cultural contexts. We did not find structural invariance or invariance of factor variances and covariances. The correlations among the four goals were different for Hong Kong Chinese and Filipino students. In most cases, weak measurement invariance is the minimum requirement for making cross-group comparisons. The differences in terms of the correlations among the four factors might be due to cultural differences, which can manifest themselves in the form of different correlations between psychological constructs. However, a look at the fit indices when the factor variances and covariances are constrained still indicate a relatively good fit. The RMSEA is below the cutoff point of .08, while the GFI, NFI, IFI, TLI, and CFI are well above .90. Clearly, additional research is needed in order to 
uncover the relationships among the different types of goals in various cultural contexts.

One of the interesting findings to come from this investigation is the positive correlation among the four types of achievement goals. That is, mastery goals, performance goals, social goals, and extrinsic goals were all positively correlated to each other which corroborated the observation and/or research findings on achievement goals involving Asian students (see Bernardo 2003, 2008; Chan and Lai 2007; Chang and Wong 2008; Tao and Hong 2000). It seems that these distinct types of goals are more positively correlated with each other among non-Western students. Among Western students, we would expect the correlations among these four types of goals to be weaker or to be non-significant as evidenced in previous studies (Elliot and Murayama 2008; Miller et al. 1996; Urdan 1994). Western constructs of achievement goals and learning approaches may not function in the same direction or generate the same effects in non-Western students due to differences in culture (Ho and Hau 2008). Early studies within achievement goal theory have found that the scores of Western students on mastery goals and performance goals are negatively correlated with each other. Results of the betweennetwork construct validity indicate that the four achievement goals were related to students' self-concepts. It seems that these four achievement goals are positively related to a student's positive self-concept. Students with a healthy sense of self in school are also more likely to pursue the different types of achievement goals. On the other hand, negative self-concept was generally negatively related to these achievement goals although performance goals and extrinsic goals were not significantly related to negative self-concept in the Hong Kong sample. It appears that for students with a negative self-concept are less likely to endorse these achievement goals in school. The difference in performance goals and extrinsic goals in the Hong Kong and Filipino samples deserves more research.

\section{Limitations and Future Directions}

A limitation of this study was that we only had positive and negative self-concept as measures in the between-network validity study. Future studies could widen the range of theoretically relevant constructs examined by investigating the relationship of these four types of achievement goals with other outcomes such as well-being in school (Dykman 1998; Kaplan and Maehr 1999; Sideridis 2005), academic achievement (e.g. Elliot and Murayama 2008), academic emotions (e.g. Pekrun et al. 2006, 2009, 2007), and self-esteem (e.g. Robins and Pals 2002). Furthermore, only Hong Kong students were examined in the Chinese context. This limits the generalizability of our results for the Chinese sample. Future studies could sample a wider range of Chinese high school students by including students from other places such as Mainland China, Taiwan, and Macau. With regard to the Filipino sample, we only sampled students from the Metro Manila area, which may limit the generalizability of our findings for the Philippines. Future studies could draw from a more heterogenous sample of students.

There may also be sampling biases involved given the larger proportion of females in the Filipino sample. However, previous studies have shown that gender 
differences in motivational variables are usually minimal. In addition, gender differences usually have more impact in terms of mean level differences and not on the factor structure (e.g. Martin 2007).

\section{Conclusion}

Students' achievement goals are considered crucial to understanding motivation and well-being in the classroom. However, most of the instruments used to measure achievement goals have been developed in the West and have not been validated in the new cultural contexts where they are used. Such an approach may render the results of these studies somewhat ambiguous. Thus, it is necessary to first validate an instrument when it is to be used in a new setting. This study supported the cross-cultural validity of the ISM among Hong Kong Chinese and Filipino adolescent high school students. Chinese and Filipino researchers may now use the validated measure in their quest to explore the role of achievement goals in students' academic-related and non-academic outcomes and towards the attainment of improved performance and well-being. Together, the analyses suggest rich implications for guidance counselors and classrooms teachers as well. School psychologists and guidance counselors, with the use of the instrument, may be able to profile the achievement goals of the students. The general picture of students' achievement goals can be used to support the development of students' adaptive achievement goals as they face the challenges of schooling. Further, on the part of the classroom teachers, they can work with school/educational psychologists and counselors in thinking of teaching strategies that are supportive of adaptive achievement goals. As a final note, we hope that this study represents an important step in adapting a foreign-made instrument in the study of school motivation in Asian context in particular. With the increasing interest in cross-cultural research, the challenge to produce psychometrically and psychologically sound instrument for another cultural group almost requires more effort than a literal translation (van de Vijver and Hambleton 1996). We hope the Chinese and Filipino versions of the ISM works to the direction of that challenge.

Open Access This article is distributed under the terms of the Creative Commons Attribution Noncommercial License which permits any noncommercial use, distribution, and reproduction in any medium, provided the original author(s) and source are credited.

\section{References}

Anderson, J. C., \& Gerbing, D. W. (1988). Structural equation modeling in practice: A review and recommended two-step approach. Psychological Bulletin, 103, 411-423.

Arbuckle, J. L. (2007). Amos 16 user's guide. Chicago: SPSS.

Bagozzi, R. P., \& Heatherton, T. F. (1994). A general approach to representing multifaceted personality constructs: Application to state self-esteem. Structural Equation Modeling, 1, 25-67.

Bentler, P. M. (1990). Comparative fit indices in structural models. Psychological Bulletin, 107, 238-246.

Bernardo, A. B. I. (2003). Do Filipino youth really value education? Exploring Filipino adolescents' beliefs about the abstract and pragmatic value of education and its relationship to achievement goals and learning strategies. Philippine Journal of Psychology, 36, 49-67. 
Bernardo, A. B. I. (2008). Individual and social dimensions of Filipino students' achievement goals. International Journal of Psychology, 43, 886-891.

Bernardo, A. B. I., Salanga, M. G., \& Aguas, K. M. (2008). Filipino adolescent students' conceptions of learning goals. In O. S. Tan, D. M. McInerney, G. A. D. Liem, \& A. G. Tan (Eds.), What the West can lear from the East: Asian perspectives on the psychology of learning and motivation. Charlotte: Information Age Publishing.

Chan, K., \& Lai, P. (2007). Revisiting the trichotomous achievement goal framework for Hong Kong secondary students: A structural model analysis. The Asia-Pacific Education Researcher, 16, 11-22.

Chang, W., \& Wong, K. (2008). Socially oriented achievement goals of Chinese university students in Singapore: Structure and relationships with achievement motives, goals and affective outcomes. International Journal of Psychology, 43, 880-885.

Cheng, R. (2005). Effects of social goals on student achievement motivation: The role of self-construal. Unpublished doctoral dissertation, the University of Hong Kong.

Cheung, G. W., \& Rensvold, R. B. (2002). Evaluating goodness-of-fit indexes for testing measurement invariance. Structural Equation Modeling, 9, 233-255.

Chua, Y. T. (2000). Overextended and underfunded, public schools are at the bottom of the academic ladder. Philippine Center for Investigative Journalism, vol 6. Retrieved December 2009 from http:// www.pcij.org/imag/Society/education.html.

Chua, Y. T. (2008). Inequalities in RP deprive kids of basic education-UNESCO. Downloaded from http://www.gmanews.tv/story/136688/Inequalities-in-RP-deprive-kidsof-basic-education on May 12, 2009.

Dowson, M., \& McInerney, D. M. (2001). Psychological parameters of students' social and work avoidance goals: A qualitative investigation. Journal of Educational Psychology, 93, 35-42.

Dowson, M., \& McInerney, D. M. (2003). What do students say about their motivational goals? Towards a more complex and dynamic perspective on student motivation. Contemporary Educational Psychology, 28, 91-113.

Dowson, M., \& McInerney, D. M. (2004). The development and validation of the Goal Orientation and Learning Strategies Survey (GOALS-S). Educational and Psychological Measurement, 64, 290-310.

Dweck, C. S., \& Legett, E. L. (1988). A social-cognitive approach to motivation and personality. Psychological Review, 95, 256-273.

Dykman, B. M. (1998). Integrating cognitive and motivational factors in depression: initial tests of a goalorientation approach. Journal of Personality and Social Psychology, 74, 139-158.

Eccles, J. S., Wigfield, A., \& Schiefele, U. (1998). Motivation. In N. Eisenberg (Ed.), Handbook of child psychology (5th ed., Vol. 3, pp. 1075-1095). New York: Wiley.

Elliot, A. J. (2005). A conceptual history of the achievement goal structure. In A. J. Elliot \& C. S. Dweck (Eds.), Handbook of competence and motivation (pp. 52-72). New York: The Guildford.

Elliot, A. J., \& Church, M. A. (1997). A hierarchical model of approach and avoidance achievement motivation. Journal of Personality and Social Psychology, 72, 218-232.

Elliot, A. J., \& Murayama, K. (2008). On the measurement of achievement goals: Critique, illustration, and application. Journal of Educational Psychology, 100, 613-628.

Elliot, A. J., McGregor, H. A., \& Gable, S. (1999). Achievement goals, study strategies, and exam performance: A mediational analysis. Journal of Experimental Social Psychology, 91, 549-563.

Finney, S. J., \& DiStefano, C. (2006). Nonnormal and categorical data in structural equation models. In G. R. Hancock \& R. O. Mueller (Eds.), A second course in structural equation modeling (pp. 269-314). Greenwich: Information Age.

Ganotice, F. (2010). A confirmatory factor analysis of scores on Inventory of School Motivation, Sense of Self Scale, and Facilitating Conditions Questionnaire: A study using Philippine sample. The Educational Measurement and Evaluation Review, 1, 59-77.

Ganotice, F., \& Bernardo, A. (2010). Validating the factors of the English and Filipino versions of Sense $\mathrm{f}$ Self Scale. Philippine Journal of Psychology, 43, 81-99.

Ganotice, F., Bernardo, A., King, R. (2010). Validating the two language versions of the Inventory of School Motivation among Filipino bilingual students. Manuscript submitted for publication (copy on file with author).

Hambleton, R. K. (2001). The next generation of the ITC test translation and adaptation guidelines. European Journal of Psychological Assessment, 17(3), 164-172.

Ho, I., \& Hau, K. (2008). Academic achievement in Chinese context: The role of goals, strategies, and effort. International Journal of Psychology, 2008(43), 892-897. 
Hu, L. T., \& Bentler, P. M. (1995). Measuring model fit. In R. H. Hoyle (Ed.), Structural equation modeling: Concepts, issues and applications. Thousand Oaks: Sage.

Hu, L. T., \& Bentler, P. M. (1999). Cutoff criteria for fit indexes in covariance structure analysis: Conventional criteria versus new alternatives. Structural Equation Modelling, 6, 1-55.

Hulleman, C. S., Schrager, S. M., Bodmann, S. W., \& Harackiewicz, J. M. (2010). A meta-analytic review of achievement goal measures: Different labels for the same constructs or different constructs with similar labels? Psychological Bulletin, 136, 422-449.

Kaplan, A., \& Maehr, M. L. (1999). Achievement goals and student well-being. Contemporary Educational Psychology, 24, 330-358.

Kumar, R., \& Maehr, M.L. (2007). Cultural interpretations of achievement motivation: A situated perspective. In R. Schmeck (Ed.), Culture, motivation and learning: A multicultural perspective (pp.43-66). Information Age Publishing.

Lance, C. E., Woehr, D. J., \& Fisicaro, S. A. (1991). Cognitive categorization processes in performance evaluation: Confirmatory tests of two models. Journal of Organizational Behavior, $12,1-20$.

Lau, S., Liem, A. D., \& Nie, Y. (2008). Task- and self-related pathways to deep learning: The mediating role of achievement goals, classroom attentiveness, and group participation. The British Psychological Society, 78, 639-662.

Liem, A. D., Lau, S., \& Nie, Y. (2008). The role of self-efficacy, task value, and achievement goals in predicting learning strategies, task disengagement, peer relationship and English achievement outcome. Contemporary Educational Psychology, 33, 486-512.

Little, T. D., Cunningham, W. A., Shahar, G., \& Widaman, K. F. (2002). To parcel or not to parcel: Exploring the question weighing the merits. Structural Equation Modeling, 9, 151-173.

Maehr, M. (1984). Meaning and motivation: Toward a theory of personal investment. In R. Ames \& C. Ames (Eds.), Research on motivation in education: Student motivation (Vol. 1, pp. 115-207). Orlando: Academic.

Maehr, M. L., \& McInerney, D. M. (2004). Motivation as personal investment. In D. M. McInerney \& S. Van Etten (Eds.), Big theories revisited (pp. 61-90). Greenwich: Information Age Publishing.

Maehr, M. L., \& Zusho, A. (2009). Achievement goal theory: The past, present, and future. In K. Wentzel \& A. Wigfield (Eds.), Handbook of motivation at school (pp. 77-104). New York: Routlege.

Manneesriwongul, W., \& Dixon, J. K. (2004). Instrument translation process: a methods review. Journal of Advanced Nursing, 48(2), 175-186.

Marsh, H. W. (1997). The measurement of physical self-concept: A construct validation approach. In K. Fox (Ed.), The physical self-concept: From motivation to well-being (pp. 27-58). Champaign: Human Kinetics.

Martin, A. (2007). Examining a multidimensional model of student motivation and engagement using a construct validation approach. British Journal of Educational Psychology, 77, 413-444.

McGregor, H., \& Elliot, A. (2002). Achievement goals as predictors of achievement-relevant processes prior to task engagement. Journal of Educational Psychology, 94, 381-395.

McInerney, D. M. (2008). Personal investment, culture and learning: Insights into school achievement across Anglo, Aboriginal, Asian and Lebanese students in Australia. International Journal of Psychology, 43, 870-879.

McInerney, D. M., \& Ali, J. (2006). Multidimensional and hierarchical assessment of school motivation: Cross-cultural validation. Educational Psychology, 26, 595-612.

McInerney, D. M., \& Liem, G. A. D. (2009). Achievement motivation in cross-cultural context: Application of personal investment theory in educational settings. In A. Kaplan, S. A. Karabenick, \& E. De Groot (Eds.), Culture, self, and motivation: Essays in honor of Martin L. Maehr (pp. 213-241). Greenwich: Information Age Publishing.

McInerney, D. M., \& Sinclair, K. E. (1991). Cross cultural model testing: Inventory of school motivation. Educational and Psychological Measurement, 51, 123-133.

McInerney, D. M., Roche, L. A., McInerney, V., \& Marsh, H. W. (1997). Cultural perspectives on school motivation. American Educational Research Journal, 34, 207-236.

McInerney, D. M., Yeung, S. Y., \& McInerney, V. (2001). Cross cultural validation of the Inventory of School Motivation (ISM). Journal of Applied Psychological Measurement, 2, 134-152.

McInerney, D. M., Marsh, H. W., \& Yeung, A. S. (2003). Toward a hierarchical model of school motivation. Journal of Applied Measurement, 4, 335-357.

McInerney, D. M., Dowson, M., \& Yeung, A. (2005). Facilitating conditions for school motivation: Construct validity and applicability. Educational and Psychological Measurement, 65, 1046-1066. 
Midgley, C., Maehr, M.L., Hruda, L., Anderman, E., Freeman, K. et al. (2000). Manual for the adaptive pattern of learning scales. Ann Arbour.

Miller, R. B., Greene, B. A., Montalvo, G. P., Ravindran, B., \& Nichols, J. D. (1996). Engagement in academic work: The role of learning goals, future consequences, pleasing others, and perceived ability. Contemporary Educational Psychology, 21, 388-422.

Pajares, F., Britner, S. L., \& Valiante, G. (2000). Relation between achievement goals and self-beliefs of middle school students in writing and science. Contemporary Educational Psychology, 25, 406-422.

Pekrun, R., Elliot, A. J., \& Maier, M. A. (2006). Achievement goals and discrete achievement emotions: A theoretical model and prospective test. Journal of Educational Psychology, 98, 583-597.

Pekrun, R., Frenzel, A., Goetz, T., \& Perry, R. P. (2007). The control-value theory of achievement emotions: An integrative approach to emotions in education. In P. A. Schutz \& R. Pekrun (Eds.), Emotion in education (pp. 13-36). San Diego: Academic.

Pekrun, R., Elliot, A. J., \& Maier, M. A. (2009). Achievement goals and achievement emotions: Testing a model of their joint relations with academic performance. Journal of Educational Psychology, 1, 115135.

Pintrich, P. R. (2000). Multiple goal, multiple pathways: The role of goal orientation in learning and achievement. Journal of Educational Psychology, 26, 265-280.

Robins, R. W., \& Pals, J. L. (2002). Implicit self-theories in the academic domain: Implications for goal orientation, attributions, affect, and self-esteem change. Self and Identity, 1, 313-336.

Roeser, R. W., Strobel, K. R., \& Quihuis, G. (2002). Studying early adolescents' academic motivation, social-emotional functioning, and engagement in learning: Variable- and person-centered approaches. Anxiety, Stress, and Coping, 15, 345-368.

Salili, F. (1994). Age, sex, and cultural differences in the meaning and dimensions of achievement. Personality and Social Psychology Bulletin, 20(6), 635-648.

Salili, F. (1995). Explaining Chinese motivation and achievement. In M. L. Maehr \& P. R. Pintrich (Eds.), Advances in motivation and achievement: Culture, motivation, and achievement (pp. 73-118). Greenwich: JAI.

Salili, F., Chiu, C. Y., \& Lai, S. (2001). The influence of culture and context on Students: Motivational orientation and performance. In F. Salili, C. Chiu, \& Y. Hong (Eds.), Student motivation: The culture and context of learning (pp. 221-247). London: Plenum.

Schermelleh-Engel, K., Moosbrugger, H., \& Müller, H. (2003). Evaluating the fit of structural equation models. Methods of Psychological Research Online, 8, 23-74.

Sideridis, G. D. (2005). Goal orientation, academic achievement, and depression: evidence in favor of a revised goal theory framework. Journal of Educational Psychology, 97, 366-375.

Tao, Y.C. (2003). Hong Kong Chinese students' learning motivation: The role of social versus individualoriented achievement motivation. Unpublished doctoral dissertation, Hong Kong University of Science and Technology.

Tao, V., \& Hong, Y. Y. (2000). A meaning system approach to Chinese students' achievement goals. Journal of Psychology in Chinese Societies, 1, 13-38.

Tuominen-Soini, H., Salmela-Aro, K., \& Niemivirta, M. (2008). Achievement goals and subjective wellbeing: A person-centered analysis. Learning and Instruction, 18, 251-266.

Urdan, T. (1994). Extending goal theory: Examining social goals and multiple goal profiles. Unpublished doctoral dissertation, The University of Michigan.

Urdan, T., \& Maehr, M. L. (1995). Beyond a two-goal theory of motivation and achievement: A case for social goals. Review of Educational Research, 65, 213-243.

van de Vijver, F. J. R., \& Hambleton, R. K. (1996). Translating tests: Some practical guidelines. European Psychologist, 1, 89-99.

van de Vijver, F. J. R., \& Poortinga, Y. H. (1982). Cross-cultural generalization and universality. Journal of Cross-cultural Psychology, 13, 387-440.

van de Vijver, F. J. R., \& Tanzer, N. K. (2004). Bias and equivalence in cross-cultural assessment: An overview. Revue Europeenne de Psychologie Appliquee, 54, 119-135.

Watkins, D. A., McInerney, D. M., \& Lee, C. (2002a). Assessing the school motivation of Hong Kong students. Psychologia, 45, 145-154.

Watkins, D. A., McInerney, D. M., Lee, C., Akande, A., \& Regmi, M. (2002b). Motivation and learning strategies: A cross-cultural perspective. In D. M. McInerney \& S. Van Etten (Eds.), Research on sociocultural influences on motivation and learning: Volume 2 (pp. 329-343). Connecticut: Information Age Publishing. 
Watkins, D., McInerney, D., Akande, A., \& Lee, C. (2003). An investigation of ethnic differences in the motivation and strategies for learning of students in desegregated South African schools. Journal of Cross-Cultural Psychology, 34, 189-194.

Watkins, D., McInerney, D. M., \& Boholst, F. A. (2003). The reliability and validity of the Inventory of School Motivation: A Philippine Investigation. The Asia Pacific Education Researcher, 12, 87100 .

West, S. G., Finch, J. F., \& Curran, P. J. (1995). Structural equation models with nonnormal variables: Problems and remedies. In R. H. Hoyle (Ed.), Structural equation modeling: Concepts, issues, and applications (pp. 56-75). Thousand Oaks: Sage.

Wolters, C. A. (2004). Advancing achievement goal theory: Using goal structures and goal orientations to predict students' motivation, cognition, and achievement. Journal of Educational Psychology, 96, 236-250.

Yu, A. B., \& Yang, K. S. (1994). The nature of achievement motivation in collectivist societies. In U. Kim, H. C. Triandis, C. Kagitcibasi, S. C. Choi, \& G. Yoon (Eds.), Individualism and collectivism: Theory, method, and applications (pp. 239-250). Thousand Oaks: Sage. 